\title{
Unconventional Design of the Mechanical Crank Press Developed by the Topo- logy Optimization
}

Karel Raz, Milan Cechura, Vaclac Kubec

Department of Machine Design, Faculty of Mechanical Engineering, University of West Bohemia in Pilsen. Univerzitni 2732/8, 30100 Pilsen. Czech Republic. E-mail: kraz@rti.zcu.cz, cechura@kks.zcu.cz, vkubec@kks.zcu.cz

This article deals with the design optimization of the mechanical crank press. These presses have not any significant development changes in a long time. Mechanical press LDC 250 with nominal force 2.5 MN (250 tons) was considered as an example. This type of press can be used for operations such as bending, drawing or cutting. The topology optimization was used during this research. This papers show advantage of this design method. The optimized press has lower maximal Von-Mises stress in the structure and the maximal displacement is up to two times lower. The research was focused on the main frame (open frame with shape "C") of the press. The resistivity agaings vibrations was improved. The weight of the frame was not changed. The CAE tool NX Nastran and the optimization tool Frustum were used here. The workflow of the topological optimization is deeply described here. The comparison between the conventional (initial) and optimized design shows new approach to these machines.

Keywords: Forging, topology optimization, frame, design

\section{Introduction}

This paper deals with the improvement of mechanical properties of the forging press. Mechanical crank press LDC 250 with nominal force $2.5 \mathrm{MN}$ (250 tons) was considered. The topology optimization was used during this research. This papers show advantage of this design method. The design of mechanical crank presses is not changed for a long time. The demand on the final part are higher and accuracy has to be better. Mechanical presses, which are used nowadays, have sometimes problem with desired tolerances of the final product. Some attempts to perform the topological optimization or a redesigning of mechanical press were performed in past, but results were not implemented in new design of the press. [1]

\section{Initial design of the forging press}

Mechanical crank press LDC 250 is a two-point drawing press with a nominal forming force of 2.5 MN (250 tons) and with "C" shaped frame. The frame is performed from welded sheet-metal parts. The thickness of main parts is from $40 \mathrm{~mm}$ to $50 \mathrm{~mm}$. The press has large forging table and ram. Press can be equipped with pneumatic or hydraulic tensile holding means. This press is designed for all operations of forming of metal strips, metal sheets or coils (precision cutting, bending, space drawing. Typical product of this machine are sinks, gas cabinets, stoves, refrigerators, radiators or other small parts. [2,3]

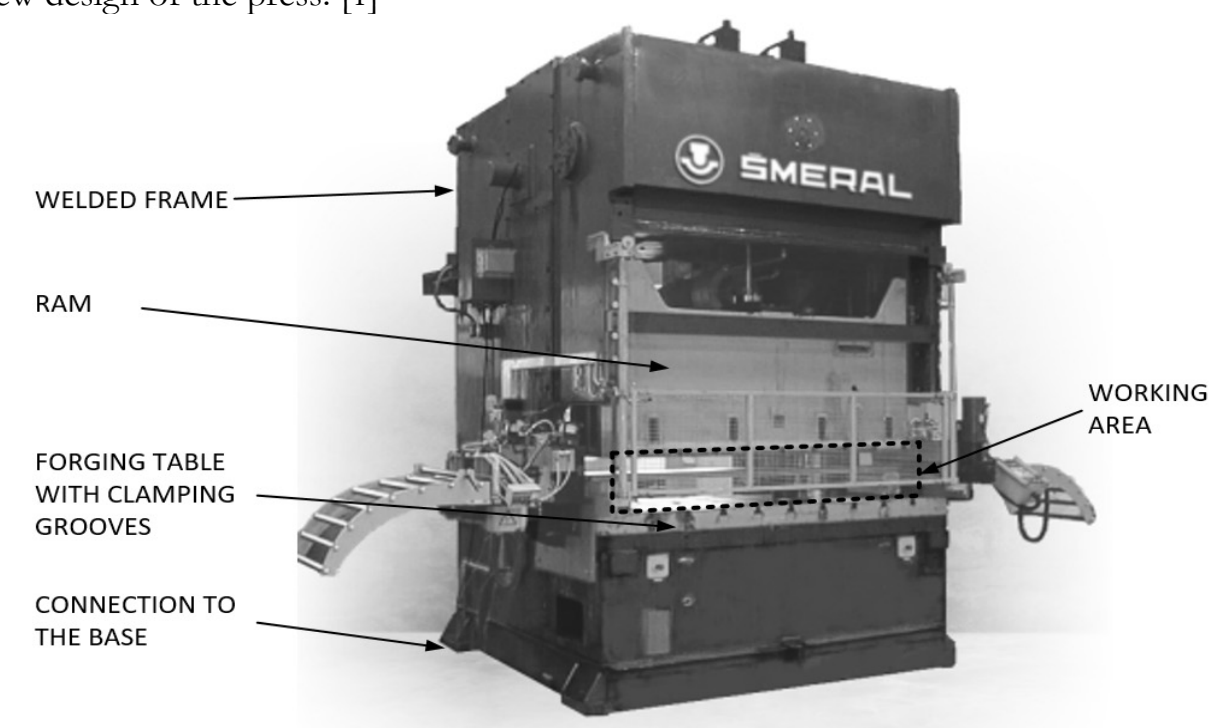

Fig. 1Mechanical crank press LDC 250 [4] 
Working area (forging table) has dimensions $2450 \times 880 \mathrm{~mm}$ and total dimension of the machine are $4000 \times 2900 \times 2700 \mathrm{~mm}$. The initial design is shown in Fig. 1.

\section{Topology optimization}

The topology optimization process was performed by usage of the advanced software tool Frustum. This solution is implemented into the Siemens NX CAD software. The topology optimization is well known mathematical method (developed in 1980s) used for the improvement of the material layout of the structure. $[5,6]$ This method is considering following inputs: loads, weight constraints, maximal allowed stress, manufacturing constraints, etc. The solution can be mathematically described as simple minimization of the objective function $\mathrm{C}(\mathrm{x})$ as follows: [7]

$$
\operatorname{Min}(C(x))=(u(x))^{T} f(x)=(u(x))^{T} K(x) u(x)
$$

\section{Where:}

$f$-global load vector containing the nodal forces $u$-global displacement vector

$K$ - global stiffness matrix

This equation (1) has to be solved in iterations (steps). It is suitable to use minimum amount of 50 iterations, which leads to good results. The generally considered minimal amount of 20 iterations is not enough, because during these iterations is mainly performed the sensitivity analysis and not the main optimization procedure.

Performed steps, which are necessary to define for the optimization workflow, are:

- Definition of FEM model and CAE solution

- Description of design objectives (here is used
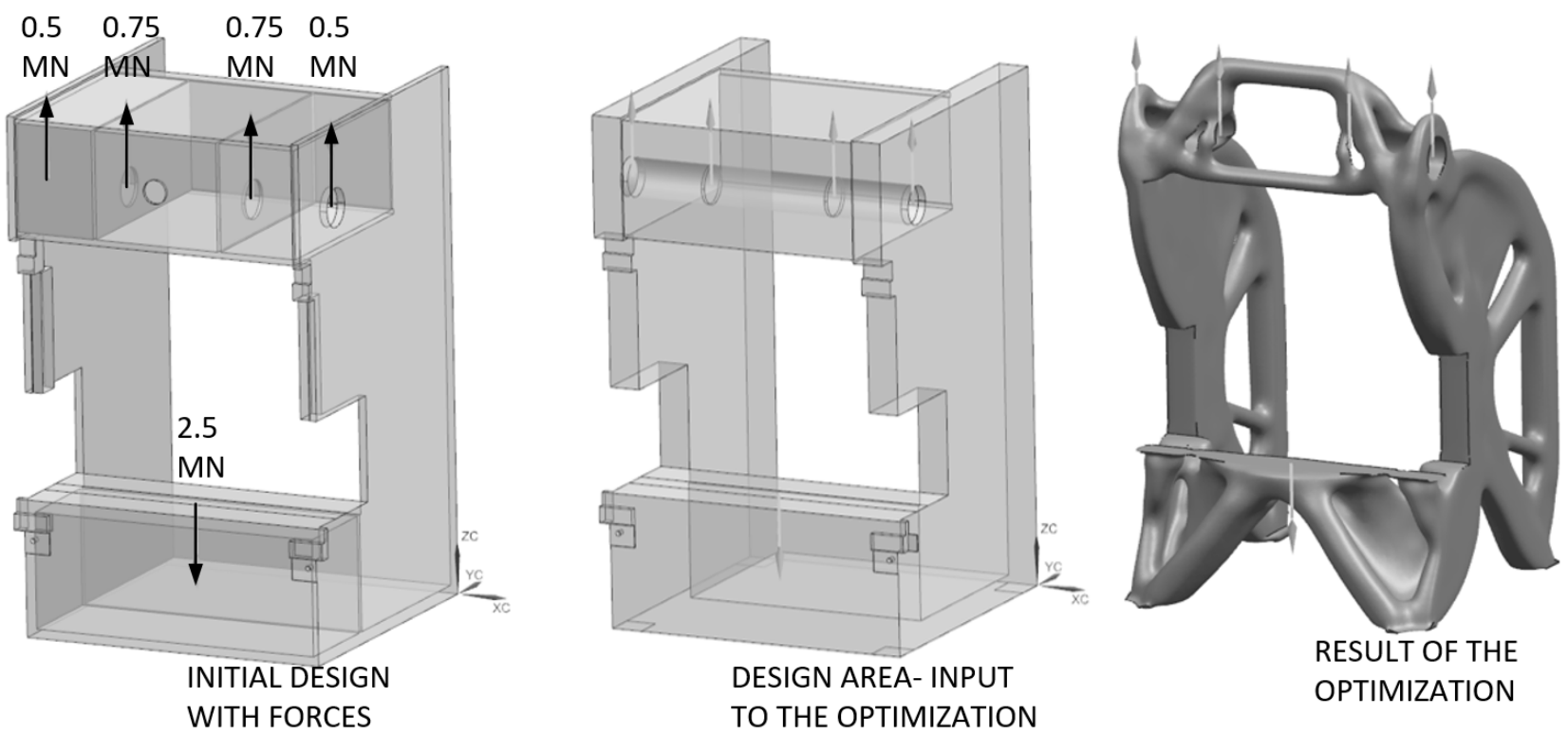

Fig. 2 Initial welded frame (left), input to the optimization- design area (middle), results from optimization (right) compliance: minimizing the weight with maximizing the stiffness)

- Description of the design area with considering frozen parts (which has to be in optimized design, such as guidance, connection to the basement, bearing locations, etc.)

- Design constraints has to be limited (upper and lower limits for weight and displacement)

- Definition of manufacturing constraints- maximum and minimum thickness, symmetry, etc.

- Solving the model

- Remodelling and verification of the new design

The following figure (Fig. 2) shows initial design of the frame. The inside cavities were removed and filled by the solid material for the topological optimization. This full-solid model was used as a design area. This design area is the most important input for the optimization. Specific faces (bearing locations and forging table connection) were fixed for the optimization and they cannot be removed by optimization process.

During the simulation was the forging table loaded by force $2.5 \mathrm{MN}$. The upper crossbeam was loaded in four individual locations of bearings. Locations of central bearings were loaded by $0.75 \mathrm{MN}$ each. Side bearings locations were loaded by $0.5 \mathrm{MN}$ each. The weight of the design area was $70.5 \mathrm{t}$. It means reduction of mass by factor 4 (to the weight 17.8t) with target of minimization of displacement and stress. These boundary conditions (displacements and forces) are described by the objective function (1). [8,9] 


\section{Remodelling of the forging press}

The remodelling process was considering the casting technology as production method of the frame. This is the only difference comparing to the initial design. Casting is more suitable with respect to the result of the optimization. Main aim was to transfer the "organic" structure of the topology results to the realistic part. It is possible to made simple changes in order to produce the optimized design as welded. The weight of the optimized and the initial frame did not change and it is $17.8 \mathrm{t}$. This limiting value was used as a constraint during definition of the topology optimization. [10] Main changes in the design are obvious from the following figure (Fig. 3).

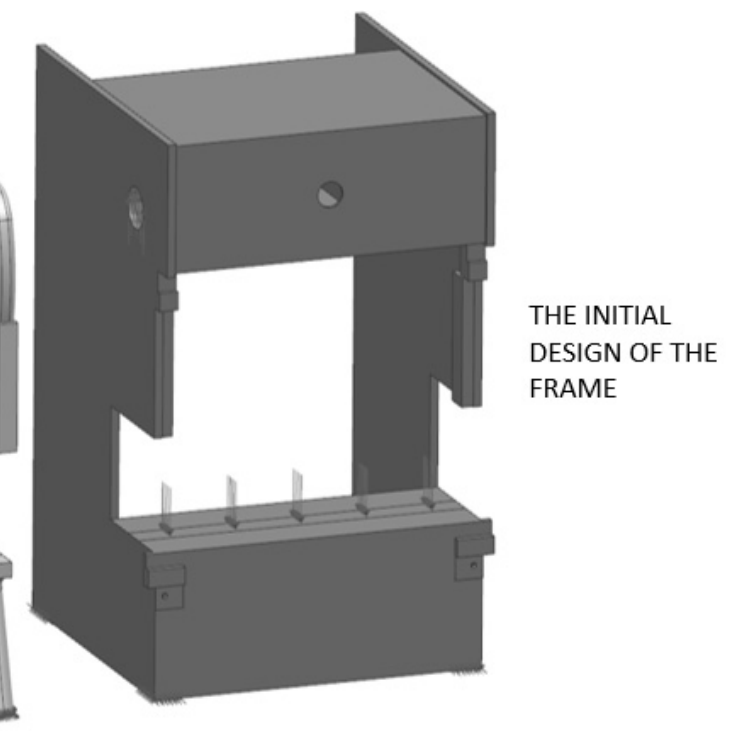

Fig. 3 Frame of the press after remodelling (left), initial frame (right), both with boundary conditions

\section{Validation of results - stress and displace- ment}

The simulation of the forging process was performed for the initial and the optimized design in order to compare them (in terms of maximal displacement and Von-Mises stress). The loading was by max- imal force 2.5 MN in the central position. The eccentric solution was also performed, the optimized frame had better results, but it is not mentioned in this paper. The solution was considering linear behaviour of the material and the static loading. It was performed in the Siemens NX pre-processor and solved by solver NX Nastran with solution SOL 101. Steel was considered as material of the frame for all performed simulations.

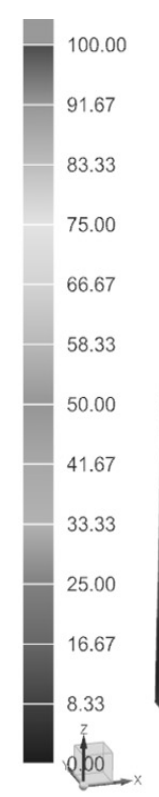

[MPa]

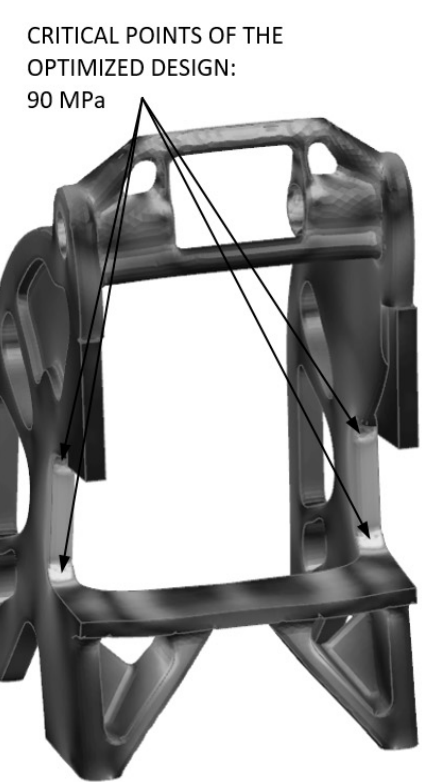

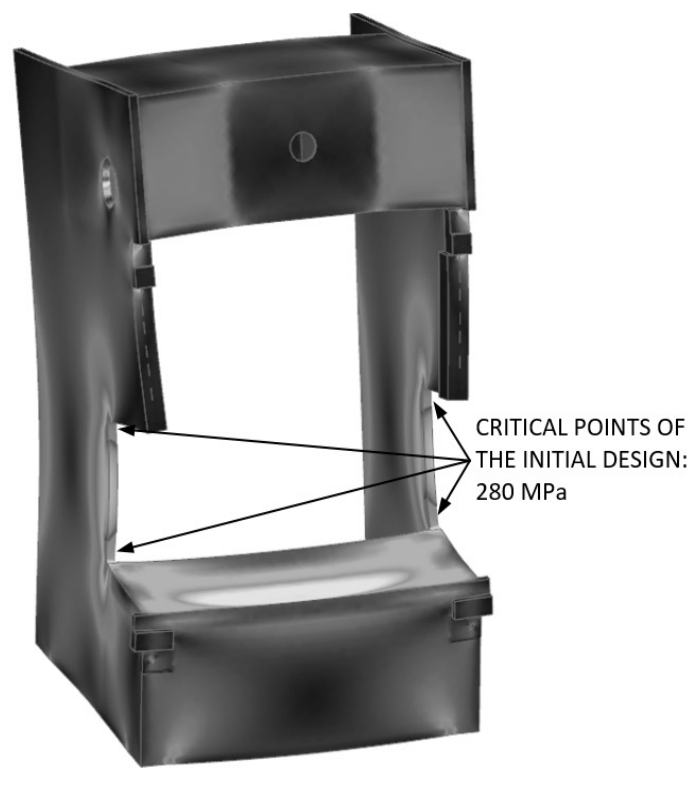

Fig. 4 Maximal Von-Mises stress for both designs [MPa] 
The previous picture (Fig. 4) shows maximum Von-Mises stress for both designs. It is obvious, that maximal loading is in the area of the forging tool and guidance. The optimized frame has more uniform distribution of the stress and the maximal values are lower. The maximal benefit of the optimized press is increasing of the accuracy. It is shown here, that the maximal displacement (Fig. 5) during loading is significantly decreased. The initial displacement was $3.1 \mathrm{~mm}$. It was decreased on the final value $1.2 \mathrm{~mm}$. The vertical stiffness of the initial design was 1.25 $\mathrm{MN} / \mathrm{mm}$. The optimized frame reached the vertical stiffness $2.25 \mathrm{MN} / \mathrm{mm}$.

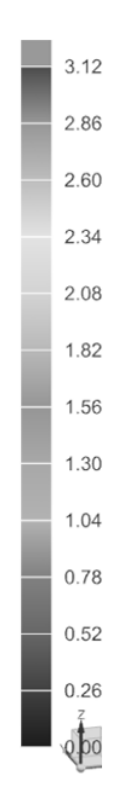

$[\mathrm{mm}]$

\section{MAXIMAL DISPLACEMENT} UNDER LOADING FOR THE OPTIMIZED DESIGN: $1.2 \mathrm{~mm}$

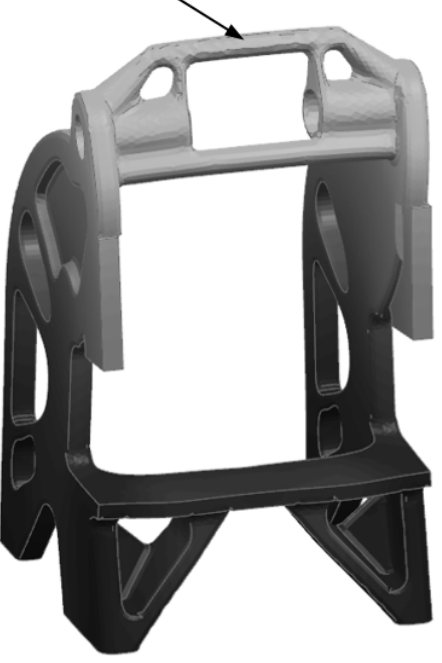

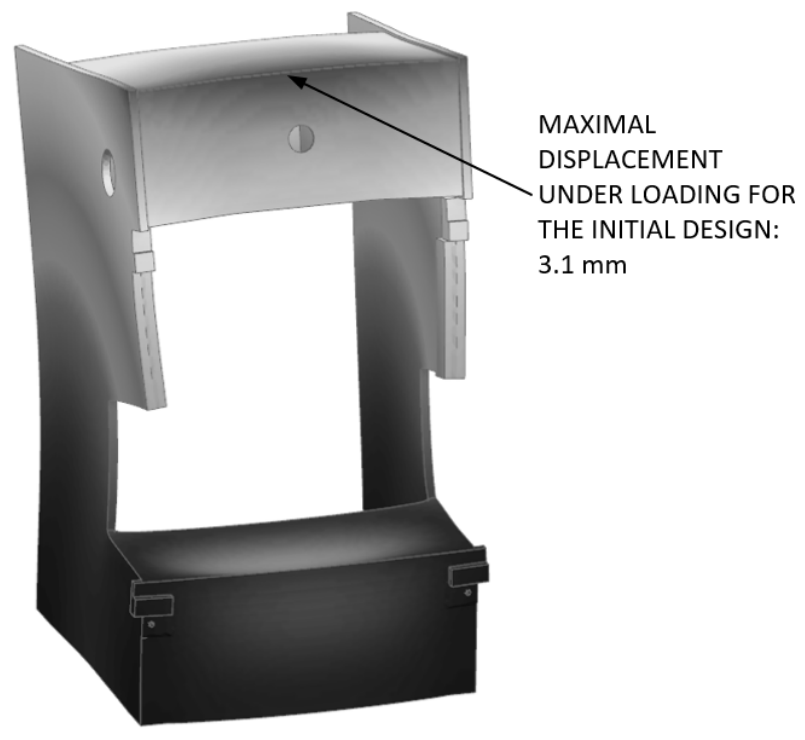

Fig. 5 Maximal displacement for both designs $[\mathrm{mm}]$

\section{Analysis of the modal behaviour}

The modal behaviour can be described as the resistivity of machine against vibrations (for specified frequency). The first modal shape was examined here (Fig. 6). It is shown, that the first frequency was increased from $5.8 \mathrm{~Hz}$ to $17.5 \mathrm{~Hz}$. It means that the optimal range of the usage (in terms of forging frequency) is wider.

This machine has guaranteed 38 working strokes

FIRST MODAL SHAPE„SIDE-BENDING“ FOR THE INITIAL DESIGN AT $5.8 \mathrm{~Hz}$

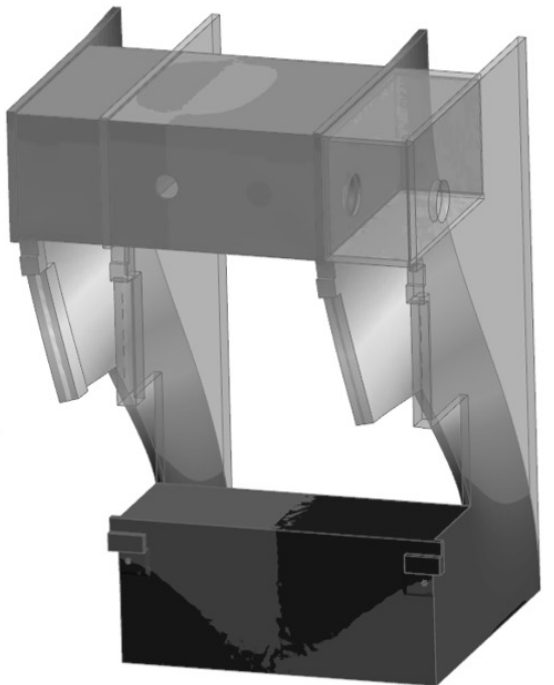

per minute (working frequency $0.64 \mathrm{~Hz}$ ). Optimized design can be used without problem with frequency up to 27 times higher, original design can be used with frequency 9 times higher. This improvement is significant. Problems with vibrations and with possibility of a damage can occur over these limits. These high frequencies are not real for production nowadays, because it is not possible to get so powerful drive and manipulation unit. [11,12]

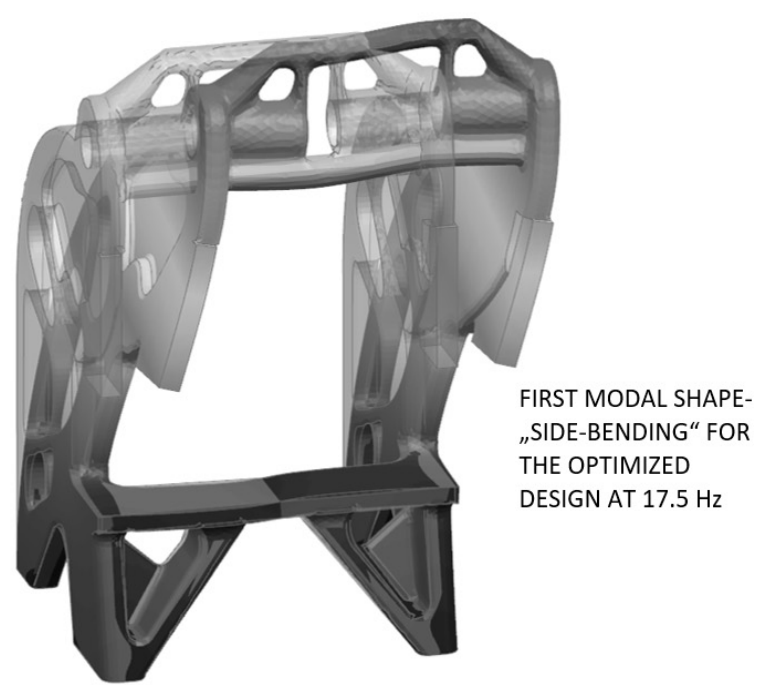

Fig. 6 First modal shape for both designs 


\section{Conclusion}

The process of redesigning of the mechanical crank press was described in this paper. For the optimization was used software Siemens NX with solvers Frustum and NX Nastran. The benefits of the topological optimization shows completely different design of mechanical crank press. It is possible to produce machine with the same weight and with up to 3times lower maximal stress. This will significantly increase lifetime (durability) of this machine with respect to $\mathrm{S}-\mathrm{N}$ curves of used material. The maximal displacement (for selected loading scenario) is 2.5 smaller. This will result to increased stiffness and higher accuracy of machine.

Analysis of the vibration resistivity was performed in terms of the determination of first modal shapes. The first natural frequency was increased from $5.8 \mathrm{~Hz}$ to $17.5 \mathrm{~Hz}$.

This research will continue in more deeply performed redesigning of the machine structure and with the creation of drawings for the production. For validation of these results will be produced a small-scaled prototype (for example by additive technology) which will be used for a validation of maximal stress and displacement. This procedure (redesigning with usage of topological optimization) will be also applied to other forging presses.

\section{Acknowledgement}

The author would like to acknowledge funding support from the Czech Ministry of Education, Youth and Sports under the project CZ.02.1.01/0.0/0.0/16_026/0008404 "Machine Tools and Precision Engineering" financed by the OP RDE (ERDF). The project is also co-financed by the European Union.

\section{References}

[1] OMER, K., ABOLHASANI, A., KIM, S., NIKDEJAD, T., BUTCHER, C., WELLS, M., ESMAEILI, S., WORSWICK, M. (2018). Process parameters for hot stamping of AA7075 and D-7xxx to achieve high performance aged products. In: Journal of Materials Processing Technology, Vol. 257, pp. 170- 179.

[2] LONDONO, J.G., BANGALORE SATISH, A., HIRIYUR. B., WOELKE, P.B. (2017). Automated Calibration of Material Models for Crash Simulation. In: International Automotive Body Council, Conference Proceedings, Dearborn.
[3] RAZ, K., CECHURA, M. (2018). Usage of topological optimization in design of mechanical forging presses.In: MM Science Journal, pp. 25812584, ISSN: 18031269, DOI: 10.17973/MMSJ.2018_11_201877

[4] SMERAL BRNO website. (2020). https://www.smeral.cz/cs/product/50/ldc250 .

[5] VOYIADJIS, G.Z., WOELKE, P.B. (2005). General non-linear finite element analysis of thick plates and shells, In: Int. J. Solids Struct, 43 $(7-8,1): 2209-42$.

[6] KALPAKJIAN, S., SCHMID, S. (2009). Manufacturing Engineering and Technology. ISBN-13: 978-9810681449.

[7] RAZ, K., CECHURA, M. (2016). Influence of hydraulic press columns connection on dynamic properties. In: MM Science Journal, pp. 13541357, ISSN: 18031269, DOI: 10.17973/MMSJ.2016_11_2016120.

[8] KUBEC, V., CECHURA, M., RAZ, K. (2014). Dynamic Behaviour of the Hydraulic Press for Free Forging. In: Procedia Engineering, DAAAM International Symposium, pp. 885-890. ISSN: 18777058.

[9] MAJERNIK, J., KMEC, J. GOMBAR, M., PODARIL, M. (2017). The Use of Simulation Programmes for the Structural Analysis and Engineering Optimization of Gating System Structures for Use with High Pressure DieCasting Technology. In: Manufacturing Technology, Vol. 17, pp. 343-347, ISSN 1213-2489.

[10] VOREL, I., JENICEK, S., KANA, J., KHODR, I., KOTESOVEC, V. (2016). Use of Optical and Electron Microscopy in Evaluating Optimization by Material-Technological Modelling of Manufacturing Processes Involving Cooling of Forgings. In: Manufacturing Technology, Vol. 16, pp. 1383-1387, ISSN 1213-2489.

[11] CECHURA, M., CHVAL, Z. (2017). Mechanical forging press for progressive working in automatic process. In: Procedia Engineering, $D A A A M$ International Symposium, pp. 367-371. ISSN: 18777058.

[12] CECHURA, M., HLAVAC, J. (2015). Direct drive of $25 \mathrm{MN}$ mechanical forging press. In: Procedia Engineering, DAAAM International Symposium, pp. 1608-1615. ISSN: 18777058. 